\title{
Disease Prevention and Health Promotion Strategies: The Possible Side Effects of Their Good Intentions
}

\author{
Mbachi Ruth Msomphora ${ }^{1}$ \& Anette Iren Langås Larsen ${ }^{2}$ \\ ${ }^{1}$ Nature and Health Science Library, UiT the Arctic University of Norway, Norway \\ ${ }^{2}$ Department of Health and Care Sciences, UiT The Arctic University of Norway, Norway \\ Correspondence: Mbachi Ruth Msomphora, Nature and Health Science Library, UiT The Arctic University of \\ Norway, Tromsø, Norway. Tel: +47-957-665-49. E-mail: mbachi.msomphora@uit.no
}

Received: May 7, 2020 Accepted: October 20, 2021 Online Published: November 1, 2021

doi:10.5539/gjhs.v13n12p1 URL: https://doi.org/10.5539/gjhs.v13n12p1

\begin{abstract}
The public health policies are principally implemented using two main strategies, namely, the population strategy and the high-risk strategy. The purpose of this article is to discuss possible side effects of the good intentions of these two main strategies. The discussions herein are made based on our perspectives and literature study methodology. Main findings portray that the disease prevention and health strategies are applied on a skewed basis, and more so, they are mainly based on medical culture and take little account of human culture. This implies that in order for individuals to comply with the health authorities' demands, they must give up their own lifestyle coping-strategies that are contradictive to the demands. Hence, the possible side effects of the disease prevention and health promotion strategies' good intentions; as the strategies have no explicit mandate to change the cultural norms and values. Therefore, we argue that adaptations to make the strategies more inclusive may promote public healthcare in the sense that it can work for everyone's lifestyle, as individuals can easily take healthy actions in the normal course of their lives.
\end{abstract}

Keywords: Public health strategies, population, high-risk, culture, gender, inequalities

\section{Introduction}

In public health, the policies are principally implemented using the two main strategies, namely, the population strategy and high-risk strategy. According to Rose (1993) and Rose et al. (2008), population strategy is a public health-oriented approach to preventive medicine and public health, which predicts that shifting the population distribution of a risk factor prevents more burden of disease than targeting people at high risk. High-risk strategy is a clinically oriented approach to preventive medicine that focuses its efforts on needy individuals with the highest levels of the risk factor ('the deviant minority with high-risk status'), and utilises the established framework of medical services (Rose, 1993; Rose et al., 2008). Literature indicates that the opinion of the majority favours combination of these two strategies for implementing public health policies. For instance, 'provision of clinics for people with alcohol problems together (as a high-risk strategy) combined with restrictions on sales (as a population strategy)', could really help in reducing health problems incurred by alcohol abuse (Kouimtsidis et al., 2021). Notwithstanding health professional meetings with individuals and families or application of systematic patient education sessions, coaching sectors and therapies outside the official systems; And more so, adoption of increasing welfare policies, since poverty seems to be the underlying cause of ill health, the two main health strategies are therefore viewed as the most important ingredient in directing the global society in the direction of good health (CSDH Final Report, 2008; Marmot et al., 2010; Pemberton, 2019). However, depending on dominant environmental-settings, such public health strategies can possibly affect the dynamics of cultural norms or lifestyles and way of thinking, as we shall see later in this article.

Culture is a pattern of ideas, values, customs and behaviours human beings create in dealing with each other. Dynamics of cultural norms accelerate when a group migrates to and incorporates components of a new culture into the existing one (Sudha \& Reddy, 2014). Based on culturally defined norms about what (in a given society) is regarded as normal or abnormal, our normative judgement is increasingly being influenced by the prestigious and dominating basic health discipline, epidemiology (Førde, 1998). Public health epidemiological facts about risk estimates and bases of action for disease prevention and health promotion shape our political and cultural norms or behaviours. They have affected our perceptions of health, illness and death, beliefs about causes of disease, 
approaches to health promotion, how illness and pain are experienced and expressed, where patients seek help, and the types of treatment patients prefer (Rose et al., 2008; Feinstein, 1988; McLennan, 1998). Such a context portrays the possible aspects of the side effects of public health strategies.

While disease prevention and health promotion strategies in the direction of good health are practiced for a good cause, there is a possibility that the strategies can change the knowledge that the society has, to knowledge that the strategies create. This implies that 'how the society or individuals behave and understand themselves is directed by health knowledge and values (Fýlkesnes \& Førde, 1992). The question here is: Does the public like the means proposed for their salvation in the direction of good health? The ideas about health, affect, as well as influence, the societies' views on, for instance, the meaning of human being and life, femininity and masculinity, normality and deviant actions, aging, body and sexuality. In this current world, it has been argued that our understanding of health and illness is just as typical and culture specific as clothes we wear, the way we eat and drink, the food we eat, our physical activities, the house we live in, the technology we use and the thoughts we think (Førde, 1998; Lian, 2004). Not only do the public health strategies change the way people think about health but also they increase risk awareness (Førde, 1998). Biological risks to diseases are reported to depend on gender (McLennan, 1998). Nevertheless, why is it that certain diseases, e.g. chronic fatigue syndrome (CFS), are now fading in prestige with an increasing number of women getting the diseases compared to men (Williams \& Gabe, 2015)? Besides, the images of health and illness have been made relevant for more and more aspects of human situations/conditions. This change has a name, namely 'medicalisation (to make medical)', i.e. what used to be normal is becoming abnormal or diseased such that more of our lives are made relevant for medical intervention (Illich, 1996). For instance, infertility is suddenly defined as a disease (Conrad, 1992; Turner, 1984). Are the epidemiological perceptions in disease prevention and health promotion appropriate to the cultural norms of what is normal for either females or males in a particular society?

The objective of this paper is to contribute a reflexive awareness regarding the possible side effects due to a good cause of disease prevention and health promotion, with focus on the inherited aspects of medicalisation and cultural change in this industrialised world. This article is based on our perspectives and published literature study. The available evidence from literature will be used to support the discussions. Based on the findings, a discussion about the possible side effects of diseases prevention and health promotion including its implications concerning health and illness will be made under each section herein. For more understanding, we will first discuss the two main health strategies of public health, and this section will have two subheadings, namely "High-risk strategy" and "Population strategy". Following this will be a Section about Medicalisation. Thereafter, another Section discussing how strategies of disease prevention and health promotion affect cultural norms (normality vs. abnormality) in the name of health will follow. Under this Section, there will be two Subheading Sections, namely: "Secularisation" and "The changing status". A Section discussing the strategies and their implications concerning gender inequalities in health will follow in order to clarify the general aspects of the possible side effects of health strategies in preventive medicine. Then finally, a conclusion is made based on the evaluation of the findings.

\section{The Two Main Health Strategies of Public Health and Their Side Effects}

As mentioned above, epidemiological science, specifically public health, has two main strategies as a means for 'disease prevention' and 'health promotion', i.e. population strategy and high-risk strategy. Industrialised society increasingly makes use of such strategies in the direction of health.

In population strategy, the measures are implemented to reduce level of risk in the whole population, shifting the whole distribution to the left (Note 1) (Rose, 1993). It aims at addressing the underlying causes of disease across the whole population. Population strategy (i.e. provision of a system for all people) can be applied using 'structural initiative' drivers, such as, modifying income distribution by tax to avoid poverty, give education to all, access to clean water, hygiene and sanitation including garbage cleaning, provision of laws, regulations and city planning, use of belts in cars and better roads, but also access to and composition of health foods to all. Besides, 'pedagogical initiatives' such as health campaigns, health checks, warnings on packs, information leaflets, TV programmes, school-based initiatives can all be used in population strategy to change the social environment in direction of health (Frank et al., 2015).

The high-risk strategy aims to focus attention on individuals at high-risk who have been identified through screening tests (Rose, 1993; Watt, 2005). It targets individuals (one-on-one) or group-based individuals at high-risk. 'Health professions' or 'healthcare' and 'activity groups', among others, can be used as the driving initiative to lower the risk, thereby changing the cultural behaviours in the name of health improvement.

Drivers of the two main health strategies as portrayed above, (including driving initiatives such as watching TV, internet browsing, and advertisements) have increasingly influenced people in using medical terminologies to 
analyse their own health; such that health has become a commodity (Barker, 2008; Maturo, 2012; Turner, 2004). The strategies, therefore, encourage people in the current society to consider health needs that otherwise they would not have thought about; and hence cultural change. New social representations of health and illness, have emerged. For example, as Maturo (2012) reports, the representation of idealised beauty and parallel treatment of cosmetic surgery in the name of health have emerged, hence the modification of the society (cultural change). What used to be regarded as normal in the society has increasingly become abnormal. But more so, health in the current world is increasingly being considered as individual responsibility. Individuals are told to avoid smoking, becoming overweight, and more so, encouraged to push back the ageing process as much as possible. Social problems are transformed into medical ones (Barker, 2008; Conrad, 2007). For instance, health professionals prescribe pharmaceutical treatments for individuals with psychiatric disorders rather than expensive psychotherapy (medicalisation problems). Besides, in clinical epidemiology, huge investments in diagnostics and genetics have led to the neglect of social causes of diseases, and to only consider them in biological terms (Clarke and Shim, 2011). Despite the evidence that in rich countries social determinants such as social status and economic conditions are more influential in health, they are seldom considered when it comes to the driving initiatives for disease prevention and health promotion. For example, "if we think that boisterous children are sick and have neurological problems and chemical imbalances, we allow ourselves to avoid looking at social problems of the family like unemployment, social cohesion in ghettos and integration of the immigrants. A pill which works on serotonin levels is easy to prescribe, and is cheaper and "cleaner" than any social policy. In supermarkets, shelves of health foods are constantly growing. Food is increasingly advertised, packed and branded in ways that connect it to medical context. We have probiotic yoghurt which reduces the risk of ictus, blueberry drinks which improve our vision, and mineral waters which "purify"” (Maturo,2012, p. 6). Therefore, the two main health strategies, i.e. population and high-risk strategy, can be seen as having possible side effects despite their good cause basis for disease prevention and health promotion.

\subsection{Population Strategy}

Population strategy is radical, powerful, and effective at population level because all risk levels are included, i.e. most 'cases' are recruited from low to moderate risk groups. It has a 'sociological' argument that says, 'we like to do what is considered normal and what others do'. However, humans, as Rose et al. (2008) notices, flourish by creativity, inventiveness, and adaptability and that implies behaviour diversity. The commission dealing with public health may endeavour to impose uniform procedures and regulations on all, but this regression to the style of the 'one-size-fits-all' is restricted by the urge of humans to be individual, which means to be different. Therefore, public health with its globalisation strategies imposes new cultures on the societies, where deviants from the imperialised cultures are left with condemnation, guilt and their social and cultural values undermined (Conrad \& Barker, 2010).

In addition, population strategy has problems of pestering people, conflict of interest e.g. difficulties in convincing older people and it must be feasible and accepted otherwise is not effective. More so, it has to be evidence-based otherwise, its implementation can be catastrophic since it covers people at a population level. It should be noted that in such a strategy, problems are predicted based on average measures rather than what the society itself considers normal (Rose et al., 2008). For instance, "if a small amount of alcohol slightly impairs a driver's judgement, then the large number of drivers who have had one or two drinks would collectively incur a large excess of accidents, even though none of them individually had an obvious problem, but current policy assumes that this is not the case" (Rose, 1993, p. 86). Thus, few high-risk individuals reflect population-wide characteristics. Therefore, population strategy calls for acceptance of a collective responsibility, and this further burdens the afflicted (Conrad \& Barker, 2010).

\subsection{High-Risk Strategy}

With high-risk strategy, it is relatively easy to motivate individuals and decision-makers because of the closeness to treatment. Compared to population strategy, high-risk strategy is relatively easy to assess the cost-benefit ratio. Its dilemma is that it includes too few of tomorrow's patients. It may reduce self-esteem when the individual is 'defined with a problem', and thereby becomes a deviant and even labelled a transgress (Rose, 1993). As already stated, the problems in high-risk strategy, such as, alcoholics, drug addicts, rioters, vandals and criminals, the obese, the handicapped, the mentally ill, the poor, the homeless, the unemployed, and the hungry, are considered as though their existence were independent of the rest of their society (Gray, 2011). But, social norms rigidly constrain how we live, therefore, individuals who transgress the limits can expect trouble. More so, high-risk strategy has the problems of medicalisation (Aronowitz, 2009). It can be costly and have the risks of neglecting the role of social determinants in shaping human health, but more so, doing more harm than good (e.g. due to 
abundance of false positive). Grazing on false-positive tests gives little benefit especially because it gives hassles to the individuals and uses money for nothing, i.e. money/time used to label individuals sick, and money/time used to free them (medical-market). High-risk strategy violates personal integrity if the reduction in self-esteem is due to the incurred medical procedures. In clinical epidemiology, 'warranty medicine' where the client should have a probability of having the disease before tested for the disease, has the problems of medicalisation (Conrad \& Barker, 2010; Foucault, 2004). The indetermined and false positive individuals are tested repeatedly, only to be free at last (impinges 'patient's' freedom). Therefore, can we consider high-risk strategy as the best way of lowering risks? Why should the health/medical professions help you to lower the risks than what you yourself could do as you do with the other risks? As Rose (1993, p. 120) argues, "much can be done by individuals themselves to improve their own health prospects, but whether or not they will actually take such action depends substantially on economic and social structures for which governments are responsible".

Looking at high-risk strategy through the lens of 'juridical medicine', lawyers, for example, are interested in false positive and not false negative, which has medicalisation problems (Polak, 2000). If you are worried about being sued or about health-insurance requirements, then you are forced to belittle your own cultural norms and values to do 'warranty medicine' in order to avoid the risks (Conrad and Barker, 2010). More individualistic preventive strategies and one-to-one interaction, are suggested to overcome the tendency of lay people to base their risk understanding on their own framework and experiences (Backett et al., 1994).

\section{Medicalisation}

According to Conrad $(2007,2005,1975)$, medicalisation can be defined as the process by which some aspects of human life come to be considered as medical problems, whereas before they were not considered pathological. It has expanded the medical categories into social spheres that were previously not medically read. As already stated, the driving forces of medicalisation include health professions, health services, the pharmaceutical industry, mass media, medical technology including consumerism and 'modern' mentality. These driving forces are initiators of the two main health strategies of public health. Therefore, based on the discussions in the Sections above, we argue that the two health strategies for disease prevention and health promotion have possible side effects, i.e. apart from cultural modification, it is portrayed that the strategies trigger the transformation of some aspects of human conditions into medical problems (medicalisation).

Medicalisation has currently added $>5000$ codes to ICD-10 coding-system (https://tinyurl.com/ydybjdcq), such that most of our lives are made relevant for medical intervention. For instance, Adult Attention Deficit-Hyperactivity Disorder (ADHD), which was formerly known as hyperactivity in children, is now, since the 1990s, seen as a disease that can be treated with medication. Kegan in a SPIEGEL interview, 2012, pointed out that $90 \%$ of 5.4 million children in USA who display the symptoms typical of ADHD do not have the disease, but "the problem is if the drugs are available to doctors, they will make the corresponding diagnosis" (Grolle and Samiha, 2012). The advocacy group, Children and Adults with Attention Deficit and Hyperactivity Disorder (CHAAD), which is supported financially by drug stores, has become a strong advocate for identifying and treating adult ADHD. According to the last interview offered by famous psychiatrist Leon Eisenberg, 2009, who is sometimes called as the discoverer of ADHD, he recognised that ADHD is diagnosed with excessive haste, making the diagnosis in cases that do not suffer from it (https://tinyurl.com/8s4hp3re). Despite the doctors best intentions, the overdiagnosis of ADHD results in increased financial waste due to treating on many occasions pharmacologically cases in which the disease does not exist and in which, if there are symptoms, these may be due to psychosocial factors, such as the divorce of the parents, changes in location or lifestyles or other personal losses, where tutoring instead of medical prescriptions would be appropriate. The excessive tendency to prescribe medication, which may be of a great help to those who suffer from disease, can be harmful if it is administered to individuals without the disease, and hence the problem of medicalisation (Grolle and Samiha, 2012; https://tinyurl.com/8s $4 \mathrm{hp} 3 \mathrm{re}$ ). Consequently, medicalisation has increased the expenses in the system. However, not all cases of medicalisation are cases of 'over-medicalisation'. Actually, medicalisation is not necessarily a negative process. It may certainly bring benefits in terms of much-needed medical recognition and validation of suffering and vital help in alleviating it (Conrad, 1975).

Despite the general trend of expanding the medical categories, the process can currently be also considered as a bidirectional (Conrad, 2007), because there can be both medicalisation and de-medicalisation over time. Masturbation and homosexuality are good case-examples for de-medicalisation, although re-medicalisation, as Conrad (2007) notices, remains possible. Nevertheless, there are two important contextual aspects affecting medicalisation, namely, secularisation and the changing status of the medical professionals. 


\section{Cultural Norms/Values and Its Implications Concerning Strategies of Disease Prevention and Health Promotion}

Culture is about those norms, values and ways of living and thinking human beings create in dealing with each other. Humans' ideas about health and general cultural norms and values in a society mutually affect each other. As such, every concept of health and illness in a given society is based on culturally defined norms, i.e. depending on what we in the society regard as normal or desirable. This, as already stated in the Introduction Section, implies that the definition of health and illness always involves normative judgements that are constantly changing and varying with time and place. The prevailing public health epidemiological facts about bases of action for disease prevention and health promotion influences and affects the ideas about health. Thus, our views and idea about health is a mirror image of the society's normative judgements influenced with the prevailing health facts. Therefore, in this new cultural setting, our images of health and illness change with the initiated strategies of disease prevention and health promotion; and as stated earlier these changes are named 'medicalisation'. As such, medicalisation is a cultural concept.

While the two main health strategies are initiated for the betterment of life or health status, they seem to be inadequately inclusive of the original cultural perspectives of the societies. In recent decades many indigenous people, policymakers and researchers worldwide have criticised the academicians for not being aware of the specific challenges various communities face with regard to research (Stordahl et al., 2015). Medical and health research for the development of better public health service for the benefit of the entire communities lack the focus on communities' cultural norms and lifestyle values (Regjeringen.no, 2020). The concept of the participation of minority communities in research is still not an integral part of the ethical research guidelines in most of the countries including Nordic countries (Stordahl et al., 2015; Regjeringen.no, 2020), and especially during this current pandemic crisis, where there is often minimal research to point the way. In Norway, for instance, during the current COVID-19 pandemic, the infection rates of COVID-19 among the minority population is larger than among the majority population (Regjeringen.no, 2020). This shows that the authorities' COVID-19 preventive measures have been useful for the majority populations but not sufficient for the minority populations, dominated by immigrant communities (Regjeringen.no, 2020). The possible explanation for this, according to the Norwegian government is that the minority populations have not well understood the infection control measures from the authorities and perhaps the authorities have not understood the challenges of the minority populations (Regjeringen.no, 2020). This calls for the stimulation of the future control measures to base on more evidenced and equal opportunity research knowledge that includes not only on, but also with the minority people.

Unless the strategies of disease and health promotion are adequately based on more evidenced and equal opportunity research, several barriers such as challenges related to information, social pressure, stigma and certain cultural conditions may not be reduced. Financial vulnerability is also highlighted as a barrier that stands in the way of complying with disease prevention and health promotion measures (Regjeringen.no, 2020). We must seriously dare to ask questions and take over both the minority perspective and not just the majority perspective in the health strategies. Otherwise the strategies have the potential risk of making people lose their original culture and are stigmatised, resulting into a new evil about which something ought to be done (Institute of Medicine (US) Committee on Crossing the Quality Chasm, 2006). When this happens, the epidemiologists and health promoters look for new causes to espouse. Through the theoretical lens of risk awareness in health, they become professional discoverers of wrongs to be righted, of situations requiring new plans of disease prevention and health promotion (Becker, 1993). Disclosure to the public of the hazards and risks from epidemiological research and public health surveillance not only changes the way people think about health, disease and illness, but also changes human values, self-identity and perspective of life; Such that our ways of eating, drinking, exercising, dressing, housing, including sexual behaviour are affected (Førde, 1998). Deviants from the standard are labelled outsiders, but deviance depends on many things extraneous to the society's usual/common behaviour. With increased definitions of what is risky, the normal gets abnormal; or what used to be a behaviour becomes a disease, with its detailed medical description including symptoms, diagnostics and treatment.

In this new cultural setting where medicine is made relevant to most aspects of human life, our images of health and illness change. For instance, if you tell the hyperactive child that 'you are sick, suffering from ADHD, which was an 'oxymoron' 30 years ago (Williams \& Gabe, 2015), then that child's way of thinking changes about his/her health. According to the new European guidelines, $90 \%$ of people over 49 years of age in a certain Norwegian community in Nord-Trøndelag are assumed to have the risks of getting cardiovascular disease due to the fact that they have higher than normal levels of cholesterol (Lian, 2016 Pers. Com.). Nevertheless, if normal (according to everyday speech) is considered as 'what is common for most people', then what is normal according to this community? Should Norwegian medical professionals recommend 'cholesterol-lowering treatment' to $90 \%$ of the 
Norwegian population? According to Conrad (1992), medicalisation has resulted in diminution of religion; and abide faith in science, rationality, and progress. Lay people are becoming dependent on experts, i.e. doctors, epidemiologists and health promoters, thereby weakening the use of family network institutions and increasing prestige and power of the medical professionals, including the penchant for individual and technological solutions to problems and the prevailing humanitarian trend.

\subsection{Secularisation}

As portrayed above the field subject dealing with disease prevention and health promotion has replaced religion as the dominant moral ideology and social control institution in modern societies (Turner, 1987; Turner, 1984; Zola, 1972). Over the past century, one could think of the illness as a punishment from not behaving, but now science replaced it. The definition of legitimate disease can objectively be produced, such as, through blood test or screening. Many conditions have become transformed from sin to crime to sickness (Conrad, 1992; Turner, 1984). The argument here is that secularisation leads to medicalisation. There is evidence to support this, e.g. gambling or infertility is suddenly defined as a disease. Other diseases such as homosexuality and nostalgia are no longer diseases. By the $1850 \mathrm{~s}$, nostalgia was losing its status as a particular disease and became rather a symptom or stage of a pathological process, i.e. a form of melancholia and predisposing condition among suicides (Boym, 2001). More evidence on this, is anorexia nervosa, which Brumberg $(1988$, p. 7$)$ sees as a type of secularised salvation:

From the vantage point of the historian, anorexia nervosa appears to be a secular addiction to a new kind of perfectionism, one that links personal salvation to the achievement of an external body configuration rather than an internal spiritual state.

\subsection{The Changing Status}

Although 'cultural change' cannot be deemed the central explanation for medicalisation (Zola, 1972; Conrad \& Schneider, 1980), the organisation and structure in health professions has an important impact. Professional dominance and monopolisation have a significant role in giving medicine the jurisdiction over which the label 'disease prevention' and 'health promotion' could be attached (Freidson, 1970). Public health workers, through their role-play as 'moral entrepreneurs', influence our ideas and views about health on issues concerning e.g. human beings and life (the meaning of it all), femininity and masculinity, normality and deviant action, aging, including body and sexuality. Normally, bone-density goes down with age, but now medicine can change what used to be 'normal'.

The promotion of health e.g. through genetic tests, may contribute to the changing status of the medical professionals. A positive finding on a genetic test, that one has a gene for a particular problem (cancer or alcoholism), may create a new medicalised status, that of 'potentially ill.' This can have an impact on one's identity, social status, and insurability (Burris et al., 2000). It may create new categories of pre-cancer, pre-alcoholism, or similar labels. This could expand medical surveillance and/or medical gaze (Armstrong, 1995; Earle, 2009).

The status of disease hierarchy depends on who is suffering, and if the disease can be diagnosed or treated. Male diseases are viewed as more serious compared to women's diseases, because, as reported by McLennan (1998), they do not face the same biological risk of disease. Breast cancer has low-status; and chronic fatigue syndrome (CFS), once diagnosed in Max Weber and Florence Nightingale, used to have high-prestige, because it was usually diagnosed in men with important positions. The disease is no longer prestigious because women are now getting it more than men (Williams \& Gabe, 2015). Childbirth is more medicalised than others, such as menopause, or contested conditions like CFS, Gulf War syndrome or multiple chemical sensitivity (Williams \& Gabe, 2015).

Usually diseases that are organ specific, and often affect men, for example, the ischemic heart that suddenly occurs and can be treated by surgery with high-technological medical-equipment, have higher status than diseases with diffuse insidious symptoms (Ingstad, 2013).

Although a combination of high-risk and population strategy in public health is increasingly recommended as the best option in 'disease prevention' and 'health promotion', the strategies portray to have changed our cultural-society to risky-cultural-society, where small hazardous problems are increasingly considered dangerous. This is probably the outcome because at present the ultimate responsibility for decisions on health policy do not lie within the public/society itself (Rose, 1993). Instead, the fashion within epidemiological research closely influences our prospective life-perspective with the struggle for life-control, prudence, self-control and renunciation (Førde, 1998). Risk-taking behaviour as well as short-sighted enjoyment and even overindulgence were predominant characteristics. Today, these attitudes are unwanted, and it is not difficult to ascertain that interdisciplinary approaches of epidemiology in public health have affected our culture in this industrialised world. 


\section{Health Strategies and Their Implications Concerning Gender Inequalities in Health}

While some public health strategies are developed for individuals at risk, most strategies have been developed for the general population, i.e. at the population-level. Nevertheless, we argue that the population-based research may not be representative, i.e. it is skewed, since, among others, a number of the health scientific research is done only on one gender e.g. on men, and lacks relevant research that also deals with the other gender, such as women (Ingstad, 2013; Løchen \& Gerdts, 2015). This, among others, is partly because women have been insufficiently included in clinical trials or analysed sex-specific differences in the data; such that in the previous decades the consideration and inclusion of men overshadowed women in clinical research design and conduct (Liu \& Mager, 2016). But more so, the use of mainly male animals in preclinical research have led to a biased literature, providing an accurate picture of underlying biological mechanisms in males only (Mogil, 2020). Notwithstanding that most chronic pain patients are women, the preclinical literature regarding pain processing and the pathology of chronic pain has historically been guided by the studies of male rodents (Mogil, 2020). Even though different types of disease may also have very similar symptoms for men and women, obviously there are important differences. For example, stress cardiomyopathy affects women more than men (Løchen \& Gerdts, 2015). In terms of acquired heart disease such as angina pectoris, women may have other symptoms of the disease that are different from men. The classic symptoms of angina pectoris, which are sultry, stinging, squeezing, and constricting pains in the middle of the chest, with radiating pain to the left arm and towards the neck and jaw, are based mainly on research conducted on men. However, women, to the contrary, may have among other more vague symptoms such as fatigue, nausea and shortness of breath. The disadvantage with such research-knowledge is that many gender-based diseases, like angina pectoris in women, are not diagnosed in time. Besides, there is a risk that the patients can be mistreated, incorrectly medicated and at worst die of the disease, e.g. heart and vascular diseases, because health personnel misinterpreted symptoms (Løchen \& Gerdts, 2015; Johnston et al., 2011; Løchen \& Njølstad, 2007). More so, despite the fact that women live longer than men and use health care to a greater extent than men, research on drugs is more often examined on men. Treatment effects cannot always be transferable between different sexes, because women and men are biologically different (Liu \& Mager, 2016; Burrowes, 2021), which, among others, is one of the determinants of health. It is well known that gender can have a say in how drugs work, and this is mostly because various hormones, i.e. feminine and masculine hormones affect female and male bodies respectively. They have different genitalia, muscle mass, breasts and hair growth. Therefore, what can be considered normal for women may not be necessarily normal for men, and vice versa. In addition, women and men have different fluid and fat levels. Such gender inequalities may affect the influence of how the drugs are absorbed and work for the sexes, especially when it comes to fat-soluble drugs. Most drugs break down in the liver, where men generally have a higher rate of degradation (disintegration rate) compared to women. This imply therefore, that women can get more effect from some drugs than men (Ingstad, 2013). As such, lack of knowledge due to skewed health research-knowledge as currently experienced, i.e. that there is great existence of the male body knowledge which does not fit the whole population, negatively affects the good intentions of the main public health strategies.

Worse still, despite the fact that women on average are about 10 years older than men when they have their first heart attack (Løchen \& Gerdts, 2015; Bergstrøm, 2015; Cho, 2017; Cleveland Clinic, 2019), the age limit to participate in medical studies has usually been the age group of $<75$ years. As Løchen and Njølstad (2007) argue, this can give a skewed result-picture because women often get acquired heart disease later in life, i.e. after reaching the age of 75. Besides, more research is carried out on breast cancer than on women's heart attack, even though heart attack kills more women (Bergstrøm, 2015). Cardiac fibrillation often affects women harder than men when they have it, such that women face a higher risk of major disabling cerebral stroke compared to men (Bergstrøm, 2015). Thus, despite the recognition today of the need to include women sufficiently in research, such that some female studies may be trying to make up for this fact and gather female-only research, there is still need to correct decades - centuries even - of gender bias in medicine and medical research (Burrowes, 2021). Until then, using skewed research-findings can unintentionally give the negative side effects of the medical interventions designed to prevent more disease burdens.

\section{Conclusion}

The findings of this article should be interpreted in consideration to the study's limitations. Our findings in this article are based on our perspectives and the published literature, and hence may differ from other people's understanding of the situation. However, due to the multicultural background of the herein authors, i.e. have both global north and south background within the field of public health and nursing. This allows the authors to complement each other and bring out different perspectives at both the majority and minority level. With such a background, in addition to literature reviewed herein, we believe that the findings of this article are trustworthy. 
Our article can contribute to better and more culturally sensitive public health strategies in disease prevention and health promotion. Nevertheless, since our article covers a wider-range of public health issues in relation to the two main health strategies, more specific systematic review studies based on the herein topic of study would deepen rather falsify our knowledge about the possible side effects of the two main health strategies.

We conclude that the information above ascertains the aspect of a reflexive awareness regarding the possible side effects due to a good cause of disease prevention and health promotion, with focus on the inherent aspects of medicalisation and cultural change in this industrialised world. The strategies relate to issues about medicalisation and individuals' ability to control their environment and influence those around them. The question is: Is this acceptable? If so, where, when and how can it be done? Beyond a reasonable doubt, public health strategies in general have a mandate to battle disease and promote health for the better. However, adaptations, to make the strategies more inclusive, will promote healthcare even better because it may work for numerous people's lifestyle. Individuals could easily take healthy actions in the course of their lives. More representative evidence-based medical-research knowledge for promotion of public health with a multi-level approach is required. The research must include more indigenous people, women and/or be gender balanced. Besides, public health strategies must allow communities up to individual level to decide their own health needs and design health programs and services to address those needs (A Public Health Strategy for Nunavut, 2008/2013: https://inyurl.com/y2egj2kv). Such issues may help to reduce the strategies' negative implications concerning health and illness, while attaining greater healthy effects within the communities. But more so, as Førde (1998) also argues, the strategies have no explicit mandate to change the cultural norms and values. Despite the salvation that 'public health workers' contribute, their role as 'moral entrepreneurs' seeking to influence people in a wide range of ways, requires a serious ethical scrutiny and debate. Unless we strive to achieve this, the social conventions and human interaction will ultimately be affected, hence the side effects.

\section{Acknowledgments}

The authors thank Ann Cox and Carolyn C Foley for reading through the paper and checking spellings and grammar including constructive comments and suggestions in writing this paper.

Special thanks to SMH (Spesialgruppen for medisin og helsefag under Norsk bibliotekforening) for the financial support that has covered the article processing charge (APC) for the open access publication of our article. But more so, SMH financial support has enabled a visible demonstration to the global community about how researchers at the Libraries and various Faculty Institutions can easily collaborate and work together in order to make a contribution to research-based knowledge in the wider society, as required.

\section{Competing Interests Statement}

The authors declare that they have no competing interests in relation to this manuscript and that there are no financial or financially competing interests to declare.

\section{References}

Armstrong, D. (1995). The rise of surveillance medicine. Sociology of health \& illness, 17(3), 393-404. https://doi.org/10.1111/1467-9566.ep10933329

Aronowitz, R. A. (2009). The converged experience of risk and disease. The Milbank Quarterly, 87(2), 417-442. https://doi.org/10.1111/j.1468-0009.2009.00563.x

Backett, K., Davison, C., \& Mullen, K. (1994). Lay evaluation of health and healthy lifestyles: evidence from three studies. British Journal of General Practice, 44(383), 277-280.

Barker, K. K. (2008). Electronic support groups, patient-consumers, and medicalization: the case of contested illness. Journal of health and social behavior, 49(1), 20-36. https://doi.org/10.1177/002214650804900103

Becker, H. S. (1993). Moral Entrepreneurs. In: Outsiders studies in the sociology of deviance (New ed., pp. 147-163). New York: Free Press.

Bergstrøm II. Heart disease is the number one killer of women in Norway. Retrieved 20 December, 2019 from http://kjonnsforskning.no/en/2015/10/heart-disease-number-one-killer-women-norway

Boym, S. (2001). The future of nostalgia. Basic books.

Brumberg, J. J. (1988). Fasting girls: The emergence of anorexia nervosa as a modern disease. Harvard University

Burris, S., Gostin, L. O., \& Tress, D. (2009). Public health surveillance of genetic information: Ethical and legal responses to social risk. In Genetics and Public Health in the 21st Century: Using Genetic Information to Improve Health and Prevent Disease. Oxford University Press. 
https://doi.org/10.1093/acprof:oso/9780195128307.003.0027

Burrowes, K. (2021). The Conversation. Academic rigour, Journalistic flair. Gender bias in medicine and medical research is still putting women's health at risk. Retrieved 23 July, 2021, from https://inyurl.com/42xjht9m

Cho, L. (2019). Women or Men - Who Has a Higher Risk of Heart Attack?: How gender is involved in coronary artery disease. Retrieved 18 December, 2019, from https://tinyurl.com/y64a598r

Clarke, A. E., \& Shim, J. (2011). Medicalization and biomedicalization revisited: technoscience and transformations of health, illness and American medicine. In Handbook of the sociology of health, illness, and healing (pp. 173-199). Springer, New York, NY. https://doi.org/10.1007/978-1-4419-7261-3_10

Cleveland Clinic. (2019). Women \& Cardiovascular Disease: Cardiovascular disease is NOT just a man's disease. Retrieved 20 December, 2019, from https://tinyurl.com/y5cwlezv

Commission on Social Determinants of Health (CSDH) Final Report. Closing the gap in a generation: health equity through action on the social determinants of health - Final report of the Commission on Social Determinants of Health. Retrieved from Geneva, World Health Organization, 2008.

Conrad, P., \& Barker, K. K. (2010). The social construction of illness: Key insights and policy implications. Journal of health and social behavior, 51(1_suppl), S67-S79. https://doi.org/10.1177/0022146510383495

Conrad, P. (2007). The medicalization of society: on the transformation of human conditions into treatable disorders (pp. 3-19). Baltimore: Johns Hopkins University Press.

Conrad, P. (2005). The shifting engines of medicalization. Journal of health and social behavior, 46(1), 3-14. https://doi.org/10.1177/002214650504600102

Conrad, P. (1992). Medicalization and social control. Annual review of Sociology, 18(1), 209-232. https://doi.org/10.1146/annurev.so.18.080192.001233

Conrad, P. (1975). The discovery of hyperkinesis: Notes on the medicalization of deviant behavior. Social problems, 23(1), 12-21. https://doi.org/10.2307/799624

Conrad, P., \& Schneider, J. W. (1980). Looking at levels of medicalization: a comment on Strong's critique of the thesis of medical imperialism. Social Science \& Medicine. Part A: Medical Psychology \& Medical Sociology, 14(1), 75-79. https://doi.org/10.1016/S0271-7123(80)90804-4

$\mathrm{CDC} /$ National Center for Health Statistics. International Classification of Diseases, (ICD-10-CM/PCS) Transition - Background. Retrieved from http://tinyurl.com/k751xvw (2015, accessed 20 December 2019).

Earle, S., Foley, P., Komaromy, C., \& Lloyd, C. E. (2009). Health, medicine and surveillance in the 21 st Century. Surveillance and Society, 6(2), 96-100. https://doi.org/10.24908/ss.v6i2.3250

Feinstein, A. R. (1988). Scientific standards in epidemiologic studies of the menace of daily life. Science, 242(4883), 1257-1263. https://doi.org/10.1126/science.3057627

Foucault, M. (2004). The crisis of medicine or the crisis of antimedicine?. Foucault Studies, 5-19. https://doi.org/10.22439/fs.v0i1.562

Frank, J., Bromley, C., Doi, L., Estrade, M., Jepson, R., McAteer, J., ... \& Williams, A. (2015). Seven key investments for health equity across the lifecourse: Scotland versus the rest of the UK. Social Science \& Medicine, 140, 136-146. https://doi.org/10.1016/j.socscimed.2015.07.007

Freidson, E. (1970). The Professional Constraction of Concepts of Illness. In Profession of medicine: a study of the sociology of applied knowledge (pp. 244-277). New York: Dodd, Mead \& Co,

Fýlkesnes, K., \& Førde, O. H. (1992). Determinants and dimensions involved in self-evaluation of health. Social science \& medicine, 35(3), 271-279. https://doi.org/10.1016/0277-9536(92)90023-J

FØrde, O. H. (1998). Is imposing risk awareness cultural imperialism?. Social science \& medicine, 47(9), 1155-1159. https://doi.org/10.1016/S0277-9536(98)00187-7

Gray, R. (2011). Commentary: Sullivan on the offspring of the female criminal alcoholic. International journal of epidemiology, 40(2), 289-292. https://doi.org/10.1093/ije/dyr007

Government of Nunavut. Developing Healthy Communities: A Public Health Strategy for Nunavut 2008 - 2013 (9781553251354,1553251350). Retrieved from Iqaluit, Nunavut: http://circumpolarhealth.org/library/Nunavut-PH-Strategy.pdf (2008, accessed 18 December 2019).

Grolle, J., \& Shafy, S. (2012). What about tutoring instead of pills. Spiegel interview with Jerome Kagan. Der 
Spiegel.

Illich I. Medisinsk nemesis. Oslo: Pensumtjeneste. Oslo: Gyldendal Norsk Forlag, 1996.

Ingstad K. Sosiologi i sykepleie og helsearbeid. Oslo: Gyldendal akademisk, 2013.

Institute of Medicine (US) Committee on Crossing the Quality Chasm: Adaptation to Mental Health and Addictive Disorders. Improving the Quality of Health Care for Mental and Substance-Use Conditions: Quality Chasm Series. Washington (DC): National Academies Press (US), 2006. Summary. Retrieved from https://www.ncbi.nlm.nih.gov/books/NBK19817/

Johnston, N., Schenck-Gustafsson, K., \& Lagerqvist, B. (2011). Are we using cardiovascular medications and coronary angiography appropriately in men and women with chest pain?. European heart journal, 32(11), 1331-1336. https://doi.org/10.1093/eurheartj/ehr009

Kouimtsidis, C., Pauly, B., Parkes, T., Stockwell, T., \& Baldacchino, A. M. (2021). COVID-19 Social Restrictions: An Opportunity to Re-visit the Concept of Harm Reduction in the Treatment of Alcohol Dependence. A Position Paper. Frontiers in psychiatry, 12, 175. https://doi.org/10.3389/fpsyt.2021.623649

Lian, O. S. (2016). Personal communication in her Lecture: HEL-3005.

Lian, O. S. (2004). Sosiologiske forståelser av helse, sykdom og medisinsk praksis. In: Mæland, J. G., Fugelli, P., Høyer, G. and Westin, S. (eds.), Sosialmedisin: i teori og praksis (pp. 101-117). Oslo: Gyldendal akademisk.

Liu, K. A., \& Dipietro Mager, N. A. (2016). Women's involvement in clinical trials: historical perspective and future implications. Pharmacy Practice (Granada), $14(1), \quad 0-0$. https://doi.org/10.18549/PharmPract.2016.01.708

Løchen, M. L., \& Gerdts, E. (2015). Kvinnehjerter: en medisinsk fagbok om vanlige hjertesykdommer (pp. 1-201). Gyldendal Norwegian Publishing.

Løchen, M. L., \& Myter, N. I. (2007). realiteter om kvinner og hjertesykdom. I: Schei B, Bakketeig L, red. Kvinner lider-menn dør (pp. 146-62). Oslo: Gyldendal.

Marmot, M. G., Allen, J., Goldblatt, P., Boyce, T., McNeish, D., Grady, M., \& Geddes, I. (2010). Fair society, healthy lives: Strategic review of health inequalities in England post-2010. London: The Marmot Review.

Maturo, A. (2012). Medicalization: current concept and future directions in a bionic society. Mens sana monographs, 10(1), 122. https://doi.org/10.4103/0973-1229.91587

McLennan W. Year Book Australia (1301.0). 12 Retrieved December 9, 2019, from http://www.ausstats.abs.gov.au/Ausstats/subscriber.nsf/0/CA25687100069892CA25688900155FCC/\$File/1 3010_1998.pdf

Mogil, J. S. (2020). Qualitative sex differences in pain processing: emerging evidence of a biased literature. Nature Reviews Neuroscience, 21(7), 353-365. https://doi.org/10.1038/s41583-020-0310-6

Pemberton, M. (2010). Why does health inequality persist? Retrieved December 9, 2019, from http://tinyurl.com/hq8bwuf

Polak, F. (2000). Thinking about drug law reform: some political dynamics of medicalization. Fordham Urb. LJ, $28,351$.

Regjeringen.no. Kunnskapsdepartementet. Setter i gang strakstiltak for å få ned smitten blant innvandrere. Retrieved from https://tinyurl.com/c5r38p

Rose, G. (1993). The strategy of preventive medicine. Paperback ed. Oxford: Oxford University Press,

Rose, G. A., Khaw, K. T., \& Marmot, M. (2008). Rose's strategy of preventive medicine: the complete original text. Oxford University Press, USA. https://doi.org/10.1093/acprof:oso/9780192630971.001.0001

Stordahl, V., Tørres, G., Møllersen, S., \& Eira-Åhren, I. M. (2015). Ethical guidelines for Sami research: the issue that disappeared from the Norwegian Sami Parliament's agenda?. International journal of circumpolar health, 74(1), 27024. https://doi.org/10.3402/ijch.v74.27024

Sudha, G., \& Reddy, K. S. (2014). Indigenous practices of culture, health and disease among Yanadis of Chittoor district, Andhra Pradesh. J. Sci, 4, 137-143.

Turner, B. S., \& Turner, B. (2004). The new medical sociology: Social forms of health and illness. WW Norton.

Turner, B. S. (1987). The Rationalization of the Body: Reflections on Modernity and Discipline. In Lash, S., and 
Whimster, S. (eds), Max Weber, rationality and modernity (pp. 222-241). London: Allen \& Unwin, 1987.

Turner, B. S. (1984). The body and society: explorations in social theory. Oxford: Blackwell.

Virtual Psych Centre. The ADHD myth: what did Leon Eisenberg really say before he died? Retrieved 23 July, 2021, from https://tinyurl.com/8s4hp3re

Watt, R. G. (2005). Strategies and approaches in oral disease prevention and health promotion. Bulletin of the World Health Organization, 83, 711-718.

Williams, S., \& Gabe, J. (2015). Peter Conrad: The Medicalisation of Society. In The Palgrave Handbook of Social Theory in Health, Illness and Medicine (pp. 615-627). Palgrave Macmillan, London. https://doi.org/10.1057/9781137355621_39

Zola, I. K. (1972). Medicine as an institution of social control. The sociological review, 20(4), 487-504. https://doi.org/10.1111/j.1467-954X.1972.tb00220.x

\section{Notes}

Note 1. Herein, "shifting the whole distribution to the left" implies having the majority of the population with low-risk level or with good health.

\section{Copyrights}

Copyright for this article is retained by the author(s), with first publication rights granted to the journal.

This is an open-access article distributed under the terms and conditions of the Creative Commons Attribution license (http://creativecommons.org/licenses/by/4.0/). 